\title{
RITMO CLIMÁTICO E CONFORTO TÉRMICO NA CIDADE DE PALMAS (TO) EM ANOS-PADRÃO SELECIONADOS
}

\section{CLIMATIC RHYTHM AND THERMAL COMFORT IN THE CITY OF PALMAS, STATE OF TOCANTINS, BRAZIL, IN SELECTED STANDARD-YEARS}

\author{
Liliane Flávia Guimarães da Silva1, Lucas Barbosa e Souza² \\ 1 Instituto Federal de Educação, Ciência e Tecnologia do Tocantins (IFTO), Palmas, TO, Brasil \\ 2 Universidade Federal do Tocantins (UFT), Porto Nacional, TO, Brasil
}

\section{RESUMO}

A presente pesquisa teve como objetivo compreender os aspectos climáticos e o conforto térmico na cidade de Palmas (TO), a partir de abordagem genética e dinâmica do clima em anos-padrão selecionados, em conjunção com índices de conforto térmico. Foram selecionados os anos de 1997 e 2013, anos-padrão confortável e desconfortável para o calor, respectivamente. Em ambos foram identificados três períodos-padrão: o primeiro, chuvoso (verão/início do outono), de ritmo oscilante dos tipos de tempo estáveis e instáveis; o segundo, seco (final do outono/inverno), de maior estabilidade atmosférica; e o último, chuvoso (primavera), que além de maior variabilidade dos elementos climáticos, apresentou os picos de calor extremo no início do período. Em relação ao ano de 1997, o ano de 2013 apresentou: temperaturas e índices mais elevados; menor precipitação e ventilação; maior número de episódios de calor excessivo; período seco mais extenso; maiores frequências de desconforto, principalmente no período noturno, fenômeno comum nas ilhas de calor. Essa configuração foi causada possivelmente pelo aumento da urbanização na cidade no ano de 2013 em relação a 1997.

Palavras-chave: Análise Rítmica, Sistemas Atmosféricos, Índices de Conforto Térmico, Discomfort Index, Palmas (TO)

\section{ABSTRACT}

The present paper aimed to understand the climatic aspects and thermal comfort in the city of Palmas, state of Tocantins, Brazil, based on genetic and dynamic approach of climate in selected standard-years, with thermal comfort indices. The years 1997 and 2013 were selected, standard-years comfortable and uncomfortable for heat, respectively. In both, three standard-periods were identified: the first, rainy (summerlearly autumn), with variable rhythm of stable and unstable weather types; the second, dry (late autumn/winter), with more atmospheric stability; and the latter, rainy (spring), which in addition to greater variance of climatic elements, it presented heat peaks at the beginning of the period. In relation to 1997, the year 2013 showed: higher temperatures and thermal indices; less precipitation and ventilation; more episodes of excessive-heat; longer dry period; higher frequencies of discomfort, especially at night, a common phenomenon in the heat islands. This configuration was possibly caused by the increase of urbanization in the city in 2013 compared to 1997.

Keywords: Rhythmic Analysis, Atmospheric Systems, Thermal Comfort Indices, Discomfort Index, Palmas (TO).

\section{INTRODUÇÃO}

A noção clássica de clima como o estado médio da atmosfera em um determinado lugar (HANN, 1908), teve como principal crítico o geógrafo francês Sorre (1951), principalmente por causa do uso exacerbado das médias e do caráter artificial e estático da representação dos fenômenos atmosféricos 
segundo a lógica das medidas de tendência central. O clima é definido por Sorre $(2006$, p. 90) como a "série de estados atmosféricos sobre determinado lugar em sua sucessão habitual". Com base nesse conceito, o geógrafo brasileiro Monteiro (1971) construiu um novo paradigma de análise do clima, denominado análise rítmica, possibilitando o entendimento do clima por meio de sequências de tipos de tempo, ou seja, por meio do ritmo climático, considerando a sua gênese (os sistemas atmosféricos que geram os tipos de tempo).

A técnica possibilita a aplicação em diversos estudos climáticos, incluindo estudos em conforto térmico, que em parte se originaram na meteorologia médica, a partir das interações entre clima e saúde. 0 conforto térmico é definido pela American Society of Heating, Refrigerating and Air Conditioning Engineers (ASHRAE, 2013, p. 3) como "that condition of mind that expresses satisfaction with the thermal environment" (a condição da mente que expressa satisfação com o ambiente térmico, tradução nossa). Do ponto de vista biometeorológico, comumente o complexo térmico é avaliado por meio de parâmetros quantitativos, denominados "índices de conforto térmico". Segundo Humphreys (1975), um dos principais objetivos dos índices é definir a série de condições do ambiente térmico consideradas agradáveis ou toleráveis para a população envolvida.

No entanto, são raras as pesquisas que dialogam com a análise rítmica e os índices de conforto térmico, deixando lacunas no conhecimento da gênese e dinâmica do clima, onde se inserem as variáveis ambientais, que são determinantes para os estudos dos índices, principalmente em áreas externas. 0 problema é agravado em climas caracterizados por extremos de temperatura, como o da cidade de Palmas (TO). Apesar de recente, a cidade tem apresentado um acelerado processo de urbanização (RODRIGUES, 2016) e uma elevação da temperatura nos últimos anos (PIRES, 2017), superando os $40,0^{\circ} \mathrm{C}$ de temperatura máxima diária nos meses de agosto, setembro e outubro, os meses mais quentes do ano, segundo dados do Instituto Nacional de Meteorologia (INMET).

Considerando esta problemática, a presente pesquisa tem como objetivo compreender o ritmo do conforto térmico na cidade de Palmas (TO), em paralelo aos elementos climáticos, a partir de abordagem genética e dinâmica do clima em anos-padrão selecionados, em conjunção com índices de 
conforto térmico. Tais análises devem-se, em parte, aos estudos da tese de doutorado da autora, que se propõe a contribuir com o entendimento do clima e do conforto térmico na referida cidade.

\section{MATERIAL E MÉTODOS}

Para a seleção dos anos-padrão destinados à análise rítmica, foi utilizado o procedimento metodológico descrito em Silva e Souza (2017), com utilização dos mesmos dados e do mesmo índice de conforto térmico. O Discomfort Index foi selecionado pelos autores por ser um dos índices mais utilizados em congressos e periódicos específicos em climatologia, por se adequar aos dados das estações meteorológicas disponíveis para a cidade de Palmas (TO) e pela confiabilidade atribuída em recentes estudos (DE FREITAS; GRIGORIEVA, 2017). O índice foi calculado pelas seguintes equações, ambas com temperaturas e umidade relativa com leituras simultâneas:

$\mathrm{DI}_{\mathrm{T}}=0,4 .\left(\mathrm{T}_{\mathrm{d}}+\mathrm{T}_{\mathrm{w}}\right)+4,8$

Onde: $\mathrm{DI}_{\mathrm{T}} \rightarrow$ Discomfort Index (de Thom)

$\mathrm{T}_{\mathrm{d}} \rightarrow$ temperatura de bulbo seco $\left({ }^{\circ} \mathrm{C}\right)$

$\mathrm{T}_{\mathrm{w}} \rightarrow$ temperatura de bulbo úmido $\left({ }^{\circ} \mathrm{C}\right)$

Fonte: Thom $(1957 ; 1958)^{1}$ apud Landsberg $(1972$, p. 15).

$\mathrm{DI}_{\mathrm{T}}=\mathrm{T}_{\mathrm{d}}-0,55 \cdot(1-0,01 \cdot \mathrm{RH}) \cdot\left(\mathrm{T}_{\mathrm{d}}-14,5\right)$

Onde: $\mathrm{DI}_{\mathrm{T}} \rightarrow$ Discomfort Index (de Thom)

$\mathrm{T}_{\mathrm{d}} \rightarrow$ temperatura de bulbo seco $\left({ }^{\circ} \mathrm{C}\right)$

$\mathrm{RH} \rightarrow$ umidade relativa (\%)

Fonte: Giles, Balafoutis e Maheras (1990,p. 102).

A Equação 2 foi utilizada apenas quando a temperatura de bulbo úmido não estava disponível nos dados da estação meteorológica selecionada, a estação convencional do INMET, cuja localização pode ser vista na Figura 1. Foi utilizado o intervalo de conforto do índice constante em Ayoade (1996):

\footnotetext{
${ }^{1}$ Referências que constam em Landsberg (1972, p. 36):

THOM, E. C. A new concept for cooling degree days. Air Conditioning, Heating and Ventilating, v. 54, n. 6, p. 73-80, 1957. . Cooling degree-days. Air Conditioning, Heating and Ventilating, Ref. Sec. p. 65
} 
$18,9^{\circ} \mathrm{C}_{\mathrm{DIt}}<\mathrm{DI}_{\mathrm{T}} \leq 25,6^{\circ} \mathrm{C}_{\mathrm{DIt}}$ (Desconforto para o frio $\leq 18,9^{\circ} \mathrm{C}_{\mathrm{DIt}}$ e Desconforto para o calor $>$ $\left.25,6^{\circ} \mathrm{C}_{\mathrm{DIt}}\right)$. Foram utilizados os dados dos três horários-padrão, 00h, $12 \mathrm{~h}$ e $18 \mathrm{~h}$ UTC, ou seja, $21 \mathrm{~h}, 9 \mathrm{~h}$ e 15 h no horário local.

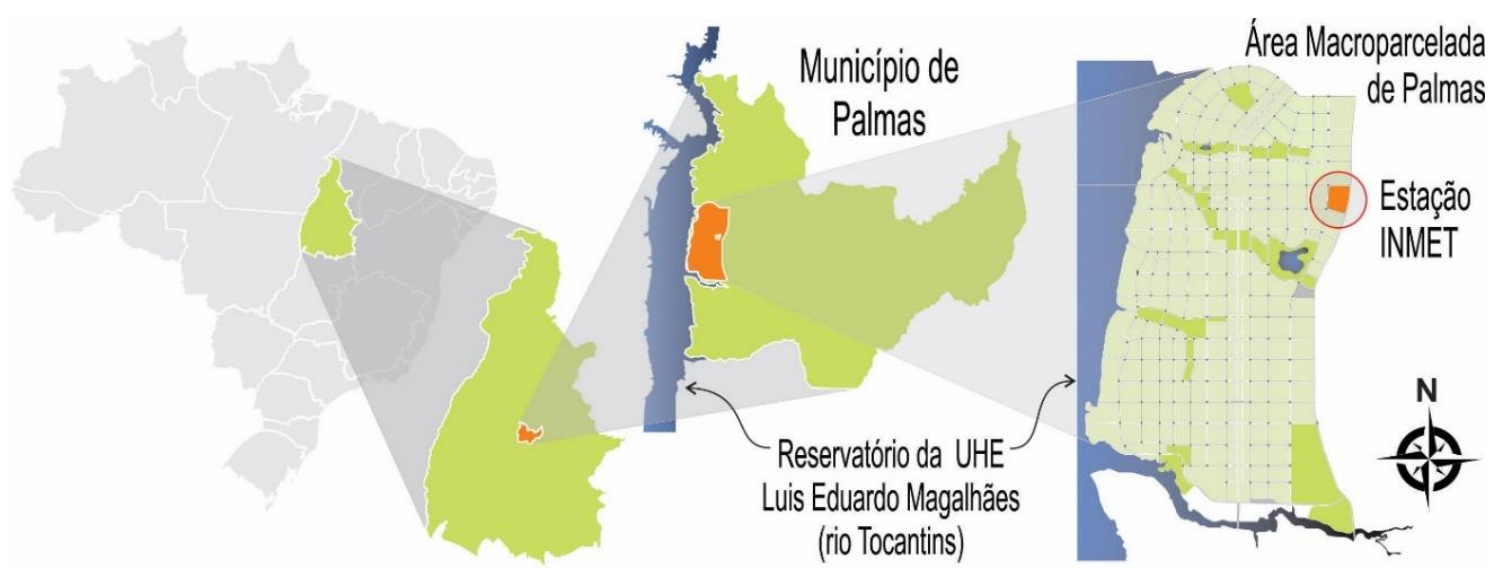

Figura 1. Localização da Estação Convencional do INMET em Palmas (TO). Fonte: Silva e Souza (2017, p. 61).

Com base na análise de Silva e Souza (2017), foram selecionados os anos de 1997, classificado por como "ano-padrão confortável", e o ano de 2013, classificado como "ano-padrão desconfortável para 0 calor", sendo analisados individualmente, como também, a partir de suas principais diferenças. Nos dois anos analisados, só ocorreram valores do índice DIT nos intervalos de conforto e de desconforto para calor, não existindo valores de desconforto para frio, como já tinha sido verificado por Silva e Souza (2017).

\section{O ANO DE 1997: ANO-PADRÃO CONFORTÁVEL}

O comportamento de todos os elementos climáticos em paralelo ao índice DIT, pode ser visto no gráfico de análise rítmica dos dados climáticos da cidade de Palmas (TO), do ano de 1997, na Figura 2. 


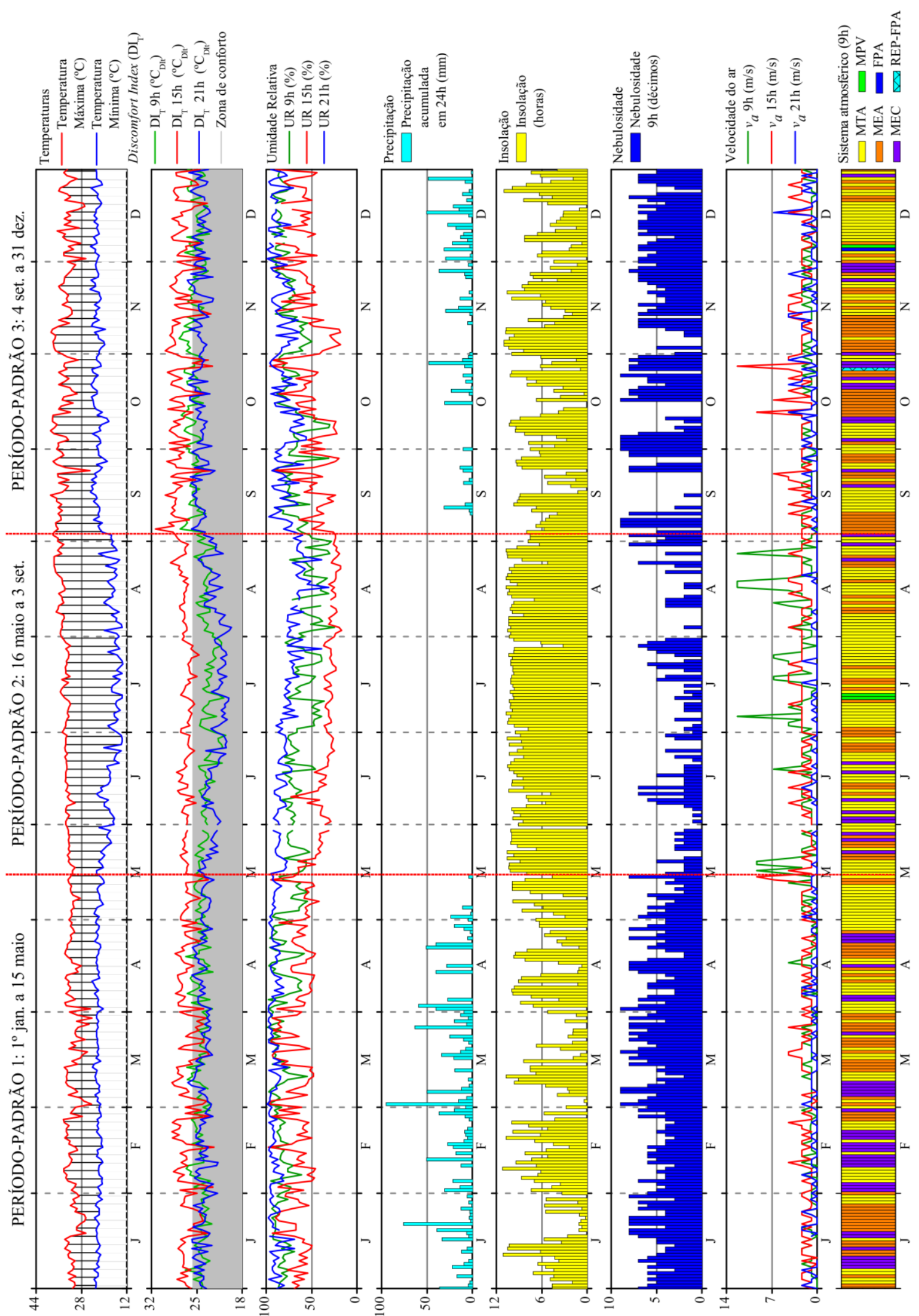

Figura 2. Gráfico de Análise rítmica da cidade de Palmas (TO), do ano de 1997. Fonte: Elaborado pela autora (2018), a partir de dados de INMET (2016).) 
Considerando os dados válidos, este ano apresentou maior frequência do índice DIT no intervalo de conforto térmico que no intervalo de desconforto para calor. As maiores frequências de conforto encontraram-se no horário noturno, seguido do horário matutino, com os menores percentuais no

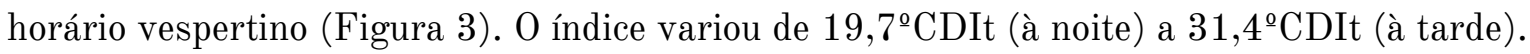

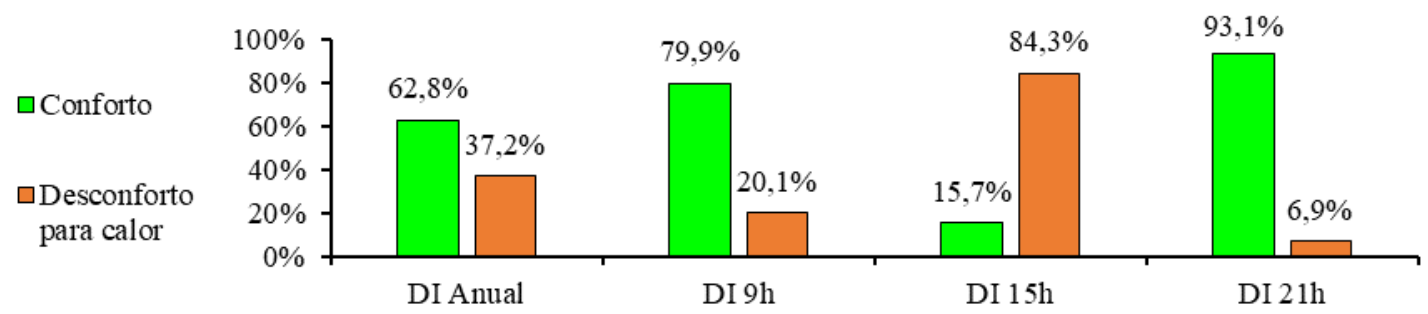

Figura 3. Frequências anual e horárias do DIT nos intervalos de conforto e desconforto para o calor, no ano de 1997 (hora local). Fonte: Elaborado pela autora (2018), a partir de dados de INMET (2016).

As temperaturas máximas variaram de 24,3 a $39,0^{\circ} \mathrm{C}$ e as mínimas de 13,5 a $25,0^{\circ} \mathrm{C}$, enquanto a umidade relativa variou de 17 a $99 \%$, e os ventos chegaram a velocidades de até $12,3 \mathrm{~m} / \mathrm{s}$. Na rosa dos ventos da Figura 4, com a frequência anual da velocidade do ventos por direção, percebeu-se que predominou o vento de direção leste, seguido da direção nordeste e sul. O ano de 1997 apresentou velocidades do vento maiores que a média identificada por Silva e Souza $(2016)^{2}$, chegando aos intervalos de brisa forte e vento fresco (acima de $7,4 \mathrm{~m} / \mathrm{s}$ ) em várias direções, porém, com um pouco mais de calmarias, $22,9 \%$ contra os $15,5 \%$ identificados pelos autores citados.

Todas essas direções confirmam a atuação predominante da Massa Tropical Atlântica (MTA) e da Massa Equatorial Atlântica (MEA) sobre Palmas neste ano, e menor frequência da Massa Equatorial Continental (MEC), como pode ser visto na Figura 5. Os sistemas polares e frontais, Massa Polar Velha (MPV), Frente Polar Atlântica (FPA) e Repercussão da Frente Polar Atlântica (REP-FPA), ocorreram em apenas cinco dias, totalizando 1,4\% em todo o ano de 1997. Percebeu-se uma maior participação da MTA nos intervalos de conforto no mesmo horário da identificação dos sistemas atmosféricos (referente às 9h), quase a metade das ocorrências. Nos intervalos de desconforto, a MEA

\footnotetext{
${ }^{2}$ Os autores utilizaram dados da estação automática do INMET entre os anos de 2005 e 2015, cuja velocidade média do vento foi de $1,65 \mathrm{~m} / \mathrm{s}$, enquanto a média do ano de 1997 foi de $1,94 \mathrm{~m} / \mathrm{s}$.
} 
apresentou maior participação, mas a MTA também teve frequência expressiva, com pequena diferença para a MEA.

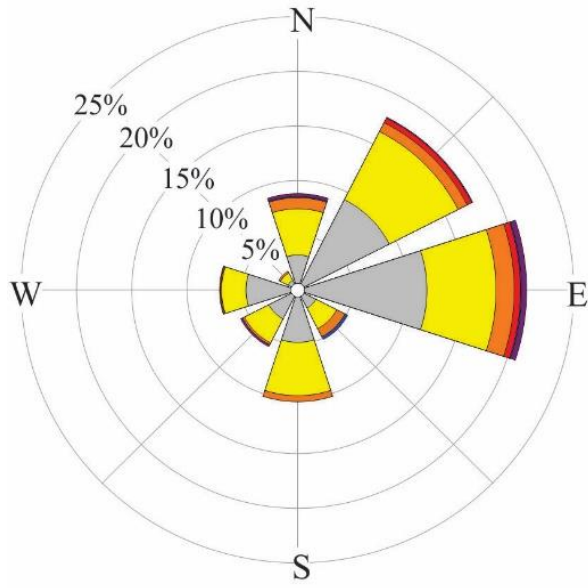

\section{7}

LEGENDA

(Escala de Beaufort)

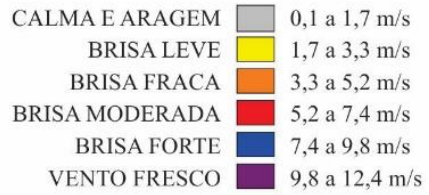

Calmarias: $22,9 \%$

Figura 4. Frequência anual da direção e velocidade dos ventos, no ano de 1997. Fonte: Elaborado pela autora (2018), a partir de dados de INMET (2016).
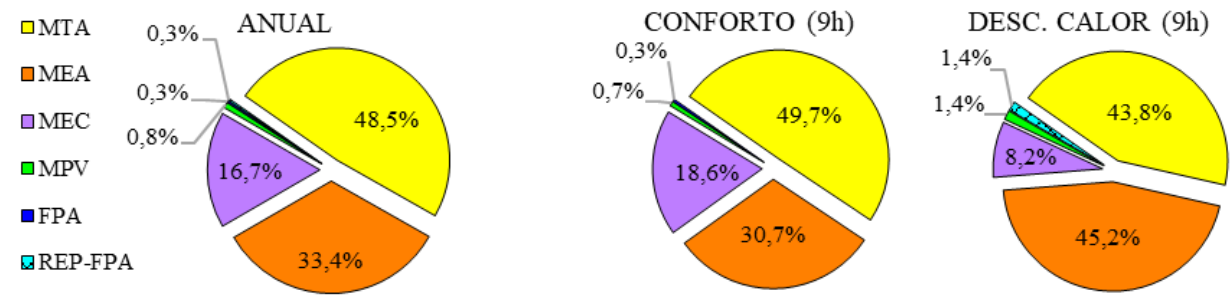

Figura 5: Frequência anual dos sistemas atmosféricos atuantes e da participação nos intervalos de conforto e desconforto para o calor do DIT, no ano de 1997. Fotos: Elaborado pela autora (2018), a partir de dados de INMET (2016).

A precipitação total anual foi de 2107,2mm, uma das maiores da série de 1997 a 2016, sendo um dos poucos anos que superaram os 2000,0mm anuais. O ano de 1997 foi um ano de maior precipitação, maiores velocidades dos ventos e menores temperaturas, apesar de ter sido um ano sob a ocorrência de El Niño, segundo o INPE (CPTEC/INPE, 2017).

Para melhor avaliação do ritmo climático na cidade de Palmas, observando principalmente o índice de conforto térmico DIT no gráfico de análise rítmica no ano de 1997 (Figura 2), e também a correspondência com os demais elementos climáticos, foram identificados três períodos homogêneos e 
distintos entre si: de $1^{0}$ de janeiro a 15 de maio (135 dias); de 16 de maio a 3 de setembro (111 dias); e de 4 de setembro a 31 de dezembro (119 dias). Estes períodos foram denominados período-padrão 1, período-padrão 2 e período-padrão 3.

A Tabela 1 apresenta os limites do índice $\mathrm{DI}_{\mathrm{T}}$, de temperatura, umidade relativa, precipitação e velocidade do vento nestes três períodos-padrão do ano de 1997. O índice apresentou os menores valores no período-padrão 2 e os maiores valores no período-padrão 3, assim como a temperatura mínima. A temperatura máxima também teve seus maiores valores no período-padrão 3, mas os menores ocorreram no períodos-padrão 1. As amplitudes de temperatura foram as menores do ano no período-padrão 1, enquanto as maiores concentraram-se no período-padrão 2 , devido à maior umidade relativa do $\operatorname{ar}^{3}$ e precipitação. Não foi registrada nenhuma precipitação no período-padrão 2, o mais seco do ano, com as menores umidades relativas, que atingiu valores críticos para a saúde e o conforto humanos. Contrastando com estes valores, o período-padrão 1 acumulou 66,9\% de toda a precipitação daquele ano, que associada às menores velocidades do ar, contribuiu com as maiores umidades relativas no início do ano.

\begin{tabular}{|c|c|c|c|c|c|c|c|}
\hline $\begin{array}{c}\text { Período- } \\
\text { Padrão }\end{array}$ & $\begin{array}{c}\mathrm{DI}_{\mathrm{T}} \\
\text { Mín. - Máx. } \\
\left({ }^{\circ} \mathrm{C}_{\mathrm{DIt}}\right)\end{array}$ & $\begin{array}{c}\text { Temp. } \\
\text { Máxima } \\
\quad\left({ }^{\circ} \mathrm{C}\right)\end{array}$ & $\begin{array}{c}\text { Temp. } \\
\text { Mínima } \\
\quad\left({ }^{\circ} \mathrm{C}\right)\end{array}$ & $\begin{array}{l}\text { Amp. temp. } \\
\text { Mín. - Máx. } \\
\quad\left({ }^{o} \mathrm{C}\right)\end{array}$ & $\begin{array}{c}\text { UR } \\
\text { Mín. - Máx. } \\
(\%)\end{array}$ & $\begin{array}{l}\text { Prec. } \\
\text { Acum. } \\
\text { (mm) }\end{array}$ & $\begin{array}{c}\text { Vel. } \\
\text { vento } \\
\text { Máxima } \\
(\mathrm{m} / \mathrm{s})\end{array}$ \\
\hline $1(1 / 1-15 / 5)$ & $21,7-28,8$ & $\begin{array}{l}24,3- \\
34,5\end{array}$ & $\begin{array}{l}20,0- \\
24,3\end{array}$ & $1,6-13,1$ & $42-99$ & 1408,8 & 9,3 \\
\hline $2(16 / 5-3 / 9)$ & $19,7-29,1$ & $\begin{array}{l}30,2- \\
38,1\end{array}$ & $\begin{array}{l}13,5- \\
22,7\end{array}$ & $8,5-23,0$ & $17-95$ & 0,0 & 12,3 \\
\hline $\begin{array}{l}3(4 / 9- \\
31 / 12)\end{array}$ & $22,2-31,4$ & $\begin{array}{l}25,0- \\
39,0\end{array}$ & $\begin{array}{l}18,4- \\
25,0\end{array}$ & $3,5-19,9$ & $18-99$ & 698,4 & 12,3 \\
\hline
\end{tabular}

Tabela 1. Limites do índice DIT, de temperatura, umidade relativa, precipitação e velocidade do vento para cada períodopadrão do ano de 1997. Fonte: Elaborado pela autora (2018), a partir de dados de INMET (2016).

\footnotetext{
${ }^{3}$ As maiores umidades relativas do ar geram menores amplitudes de temperatura, pois o vapor d'água, pelo seu calor específico, equilibra as diferenças de temperaturas. Segundo Frota e Schiffer (2001), o calor específico da água é aproximadamente o dobro do da terra, portanto, a quantidade de energia necessária para elevar de um grau Celsius a temperatura de uma unidade de massa de água é quase o dobro de energia térmica para uma mesma elevação de temperatura de uma unidade de massa de terra, e o inverso também é verdadeiro (ao se esfriar, a água também perde o dobro da quantidade de energia que a terra).
} 
Na Figura 6, a seguir, verificou-se que a distribuição dos intervalos de conforto e desconforto foram bem diferentes entres os três períodos-padrão. A frequência total do primeiro e do segundo períodos foram semelhantes ao padrão anual, com percentual um pouco maior de conforto, principalmente no período-padrão 2, diferente do período-padrão 3, que apresentou maior frequência total do índice no intervalo de desconforto.

$\mathrm{Na}$ distribuição horária da frequência por período-padrão, as diferenças foram mais acentuadas. No período-padrão 1, as frequências horárias foram semelhantes ao padrão anual, cuja redução no intervalo de desconforto foi distribuída em cada horário, mas à noite, a diferença foi bem menor em relação à frequência anual (apenas 1,0\%). Nesse período, são típicas as chuvas convectivas, que ocorrem ao final do dia, o que pode ter contribuído para o conforto térmico no horário noturno.

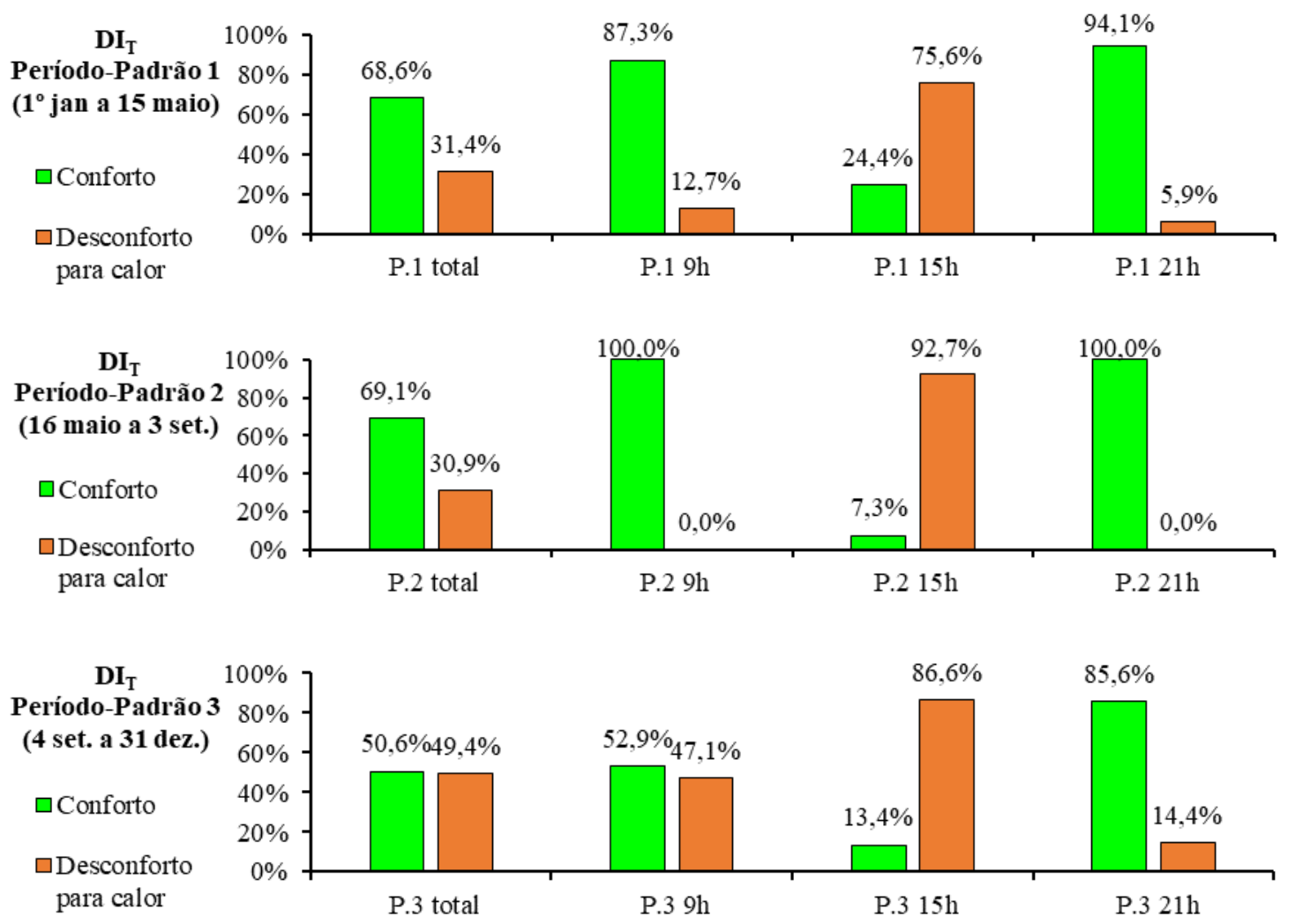

Figura 6. Frequência anual dos sistemas atmosféricos atuantes e da participação nos intervalos de conforto e desconforto para o calor do DIT, no ano de 1997. Fonte: Elaborado pela autora (2018), a partir de dados de INMET (2016).

No período-padrão 2, A frequência de desconforto para o calor ocorreu no horário vespertino exclusivamente, e com maior frequência que a anual (9,0\% a mais). Nos horários matutino e noturno 
não ocorreram frequências de desconforto. Como esse período tem como característica alta insolação, baixa nebulosidade e baixa umidade relativa do ar, levando a maiores amplitudes de temperatura, ocorre maior contraste entre o horário vespertino e os demais horários (ver Figura 2). Apesar da frequência no período vespertino ser a maior dentre os três períodos analisados, ocorreu compensação com 100,0\% de conforto pela manhã e à noite, o que gerou um balanço total de maior conforto.

No período-padrão 3, o desconforto para o calor ocorreu novamente com maior frequência no horário vespertino, com frequência um pouco maior que a anual, no entanto, nos horários matutino e noturno ocorreu maior frequência de desconforto que nos demais períodos-padrão analisados, principalmente pela manhã, com quase a metade das ocorrências $(47,1 \%)$. O que caracterizou este período foi o fato de que, apesar da frequência de desconforto à tarde não ser a maior dos três períodos analisados, à noite foi mais que o dobro da frequência anual, e pela manhã quase superou a frequência de conforto. Ou seja, as tardes permaneceram desconfortáveis, enquanto as manhãs e as noites foram as mais desconfortáveis do ano.

Acompanhando a Figura 2, foi possível perceber ainda que, no período-padrão 1, o $\mathrm{DI}_{\mathrm{T}}$ permaneceu no intervalo de desconforto com maiores valores no mês de fevereiro, e também apresentando variações mais abruptas de um dia para o outro. 0 período-padrão 2 apresentou maiores amplitudes do índice, com um aumento do $\mathrm{DI}_{\mathrm{T}}$ no horário da tarde e uma redução nos demais horários (como visto também nas frequências horárias, Figura 6). No período-padrão 3, verificou-se um retorno à configuração do período-padrão 1, ou seja, uma oscilação do índice de conforto, porém, de forma bem mais acentuada que no primeiro período e com altos valores do índice, chegando ao máximo de $31,4^{\circ} \mathrm{C} \mathrm{DI}_{\mathrm{T}}$ em setembro, o maior do ano, próximo do limite para uma intervenção médica, que é de 32,0ºDIt, segundo Thom (1959).

Provavelmente, as variações nos períodos-padrão 1 e 3 ocorreram em decorrência das diferenças entre tardes chuvosas e tardes secas, pois quando não há nebulosidade, há alta radiação devido à altura solar 
no zênite na latitude de Palmas nestas épocas do ano (em fevereiro e outubro) ${ }^{4}$, enquanto no períodopadrão 2 há maior estabilidade atmosférica.

O índice acompanhou o comportamento dos elementos climáticos nestes três períodos. No períodopadrão 1, as temperaturas mínimas foram as mais estáveis, devido ao efeito regulador da alta umidade do ar, porém, superaram os $20,0^{\circ} \mathrm{C}$, enquanto as temperaturas máximas tiveram acentuada redução, com quedas abaixo dos $28,0^{\circ} \mathrm{C}$, simultaneamente à redução do índice. As mínimas apresentaram a maior variação no período-padrão 2 , porém, foram as menores de todo o ano, chegando a $13,5^{\circ} \mathrm{C}$. Temperaturas mínimas abaixo dos $15,0^{\circ} \mathrm{C}$ eram mais frequentes até 1999 , tornando-se raras em Palmas depois do ano 2000. Já as temperaturas máximas nesse período central apresentaram um aumento gradual, atingindo seu auge no período-padrão 3, em setembro. Ainda ocorreram temperaturas máximas elevadas até a primeira quinzena do mês de novembro, enquanto as mínimas apresentaram os maiores valores, com até $25^{\circ} \mathrm{C}$. Esse comportamento gerou menores amplitudes no período inicial, maiores amplitudes no meio do ano, concentradas no mês de agosto, permanecendo um pouco altas no início do terceiro período, mas reduzindo bastante até o mês de dezembro.

Foi possível verificar também que o comportamento do índice teve estreita relação com a precipitação, e consequentemente com a umidade relativa, além da insolação e nebulosidade. As variações do índice no primeiro e no terceiro período-padrão, acompanharam as oscilações destes elementos climáticos. As reduções pontuais dos índices ocorreram geralmente em dias de chuva, com menor insolação e maior nebulosidade. Da mesma forma, a menor variação do índice acompanhou a estabilidade atmosférica no período-padrão 2, com ausência de precipitação, insolação alta e constante, e nebulosidade muito baixa. A ventilação contribuiu com a redução da umidade relativa e consequente estabilidade atmosférica neste período. No período-padrão 1, se comparado aos outros períodos-padrão, foram as reduzidas velocidades do vento que contribuíram com a elevação da umidade relativa. A velocidade do vento manteve-se a maior parte do tempo abaixo de 4,0m/s nesse período-padrão, superando os $6,0 \mathrm{~m} / \mathrm{s}$ já na transição para o período seguinte. No período-padrão 2 , o horário matutino ultrapassou os $6,0 \mathrm{~m} / \mathrm{s}$ em

\footnotetext{
${ }^{4}$ Segundo cálculos com uso das equações constantes em Iqbal (1983), na latitude de Palmas (10,19º Sul), a altura solar mais próxima de $90^{\circ}$, no primeiro semestre do ano, ocorre no verão, no dia 24 de fevereiro (com 89,96º ), enquanto no segundo semestre do ano, ocorre na primavera, no dia 19 de outubro (com 89,86º ), ambos com fotoperíodo de 12,25 horas de duração.
} 
diversos momentos, enquanto no período-padrão 3, a velocidade do vento manteve-se mais próxima dos $4,0 \mathrm{~m} / \mathrm{s}$, atingindo as maiores velocidades à tarde.

Na Figura 7, foi possível verificar na rosa dos ventos nos três períodos-padrão, que as maiores velocidades do vento ocorreram no período-padrão 2. Neste período-padrão e no período-padrão 1 , de forma semelhante à frequência anual, as maiores frequências ocorreram na direção leste e secundariamente na nordeste, mas com menores velocidades no primeiro. O período-padrão 3 apresentou padrões bem diferentes das frequências anuais e dos outros períodos do ano. A predominância foi na direção nordeste, seguido da leste, mas com frequência bem próxima das direções norte e sul.
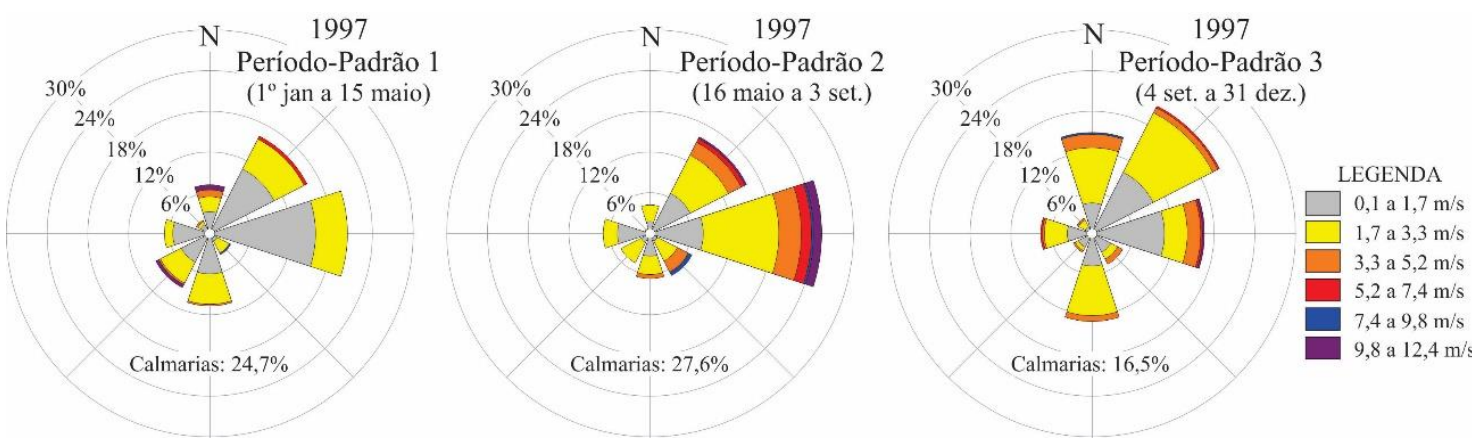

Figura 7. Frequência da direção e velocidade dos ventos nos três períodos-padrão do ano de 1997. Fonte: Elaborado pela autora (2018), a partir de dados de INMET (2016).

As direções predominantes nos períodos-padrão 1 e 2 indicaram maior frequência da MTA, que possui direção preferencialmente leste, sudeste e sul sobre o Tocantins (dependendo da posição do seu vórtice em relação ao continente americano), e no período-padrão 3, predominância dividida entre a MTA e a MEA, que possuem direção leste, no caso da MTA, e norte e nordeste, no caso da MEA. Nos gráficos da frequência das massas de ar nos três períodos-padrão (Figura 8), é possível identificar a predominância constante da MTA, porém, bem superior no período-padrão 2, com menor participação da MEA e da MEC. A MEC teve a maior participação no período padrão 1, que não apresentou nenhuma participação de sistemas polares ou frontais. A MEA apresentou maior participação no período-padrão 3, reduzindo muito a participação da MEC, mas não reduziu tanto a MTA, com obteve percentual próximo do período-padrão 1. Nos períodos-padrão 2 e 3, também se concentraram os raros 
sistemas polares e frontais do ano.

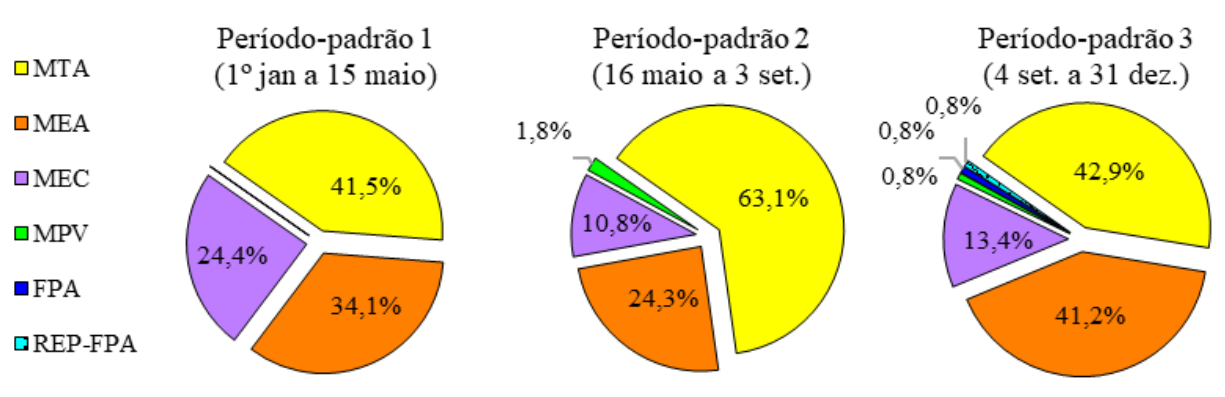

Figura 8. Frequência dos sistemas atmosféricos atuantes nos três períodos-padrão do ano de 1997. Fonte: Elaborado pela autora (2018), a partir de dados de INMET (2016).

Nos gráficos da Figura 8 e no gráfico de análise rítmica na Figura 2, foi possível verificar as diferentes formas de atuação da MTA ao longo do ano, que muda de acordo com a posição do seu centro de ação para o atlântico (SOUZA; GOMES; ROCHA, 2014; SOUZA, 2016). Como o anticiclone da MTA esteve mais distante do continente nos períodos-padrão 1 e 3, o Tocantins ficou sob atuação das suas bordas, de menor pressão atmosférica e maior umidade relativa, oportunizando também maior atuação da MEC e da MEA (maior atuação da MEC no primeiro, e da MEA no terceiro período). No meio do ano, com o anticiclone mais próximo do continente, com alta pressão atmosférica, a MTA dificultou a formação de nuvens, e consequentemente de chuva, e também a atuação de outras massas de ar. No período-padrão 1, a MEA atuou mais na redução do índice, mas no segundo período atuou mais na elevação do mesmo. Verificou-se que a MTA em atuação contínua pareceu estar associada às altas amplitudes do índice e das temperaturas, e às baixas umidades.

Em suma, pode-se verificar que o primeiro período, que coincidiu com boa parte do verão e primeira metade do outono, foi caracterizado por temperaturas máximas não tão elevadas e temperaturas mínimas constantes (gerando menores amplitudes térmicas), maior nebulosidade, menor insolação, maior umidade e precipitação, baixas velocidades do ar e relativa oscilação nos elementos climáticos. 0 índice de conforto, apesar de possuir menor frequência de desconforto, apresentou contrastes durante o dia, assim como de um dia para o outro. 
O segundo período, que ocorreu na segunda metade do outono e maior parte do inverno, teve menor variação dos elementos, sendo caracterizado por temperaturas e amplitudes térmicas crescentes, baixas umidades, precipitação nula, alta insolação, baixa nebulosidade, altas velocidades do vento, principalmente pela manhã, e maiores calmarias à noite. 0 índice apresentou estabilidade na faixa de conforto pela manhã e à noite, e pontualmente à tarde.

O terceiro período, que ocorreu no final do inverno, em toda a primavera e em alguns dias do verão, coincide com o final da estação seca e a retomada gradual das chuvas. Essas foram mais esparsas entre os dias e menos volumosas, muitas vezes sem possibilitar a redução da temperatura, sendo ainda agravado em outubro, quando o sol se encontra no zênite na latitude de Palmas. 0 período apresentou, pois, um ritmo oscilante entre tipos de tempo estáveis e instáveis, persistindo alguns valores críticos do final do período anterior, como na baixa umidade relativa, nas temperaturas máximas e no índice de conforto à tarde. Houve redução gradual dos valores máximos do índice, das temperaturas e das amplitudes de temperatura até o final do ano, à medida que as chuvas se tornaram gradativamente mais frequentes.

\section{O ANO DE 2013: ANO-PADRÃO DESCONFORTÁVEL PARA O CALOR}

O ano de 2013 apresentou menor frequência do índice DIT no intervalo de conforto térmico que o ano de 1997, quase 10,0\% a menos, como pode ser visto na Figura 9. Novamente, as maiores frequências de desconforto encontraram-se no horário vespertino (um pouco maior que em 1997), enquanto o maior percentual de conforto ocorreu pela manhã, diferente do ano de 1997, que ocorreu no horário noturno. $\mathrm{O}$ índice variou de $21,8^{\circ} \mathrm{C}_{\mathrm{DIt}}$ a $32,0^{\circ} \mathrm{C}_{\mathrm{DIt}}$ (ambos à tarde), conforme gráfico de análise rítmica (Figura 10).

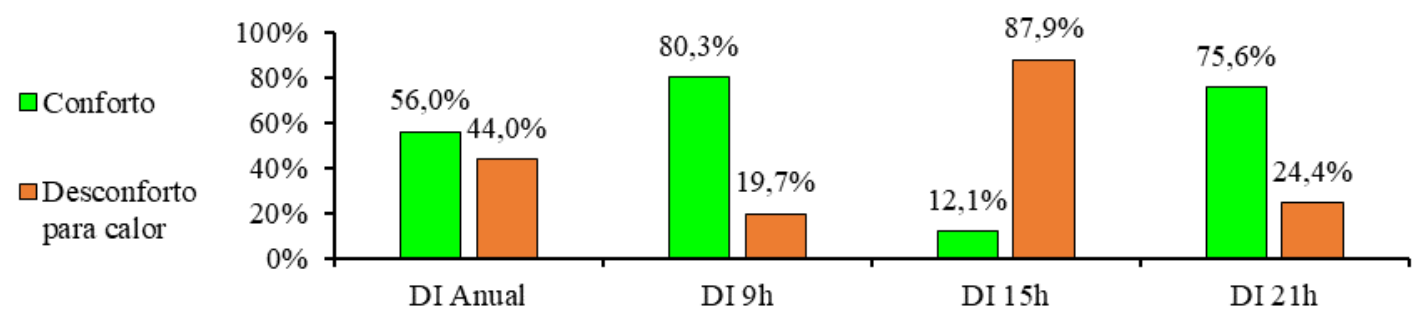

Figura 9. Frequências anual e horárias do DIT nos intervalos de conforto e desconforto para o calor, no ano de 2013. Fonte: Elaborado pela autora (2018), a partir de dados de INMET (2016). 
O horário noturno apresentou percentual de desconforto bem superior ao ano de 1997, quase 20,0\% a mais, o que possivelmente está relacionado ao aumento da urbanização da cidade de Palmas. Segundo Gartland (2010), áreas urbanas são geralmente mais quentes à noite, devido aos materiais de construção, que continuam a liberar calor e diminuir o arrefecimento, fenômeno ligado às ilhas de calor. O aumento da urbanização no entorno da Usina Hidrelétrica Luís Eduardo Magalhães, que formou o Lago de Palmas (ver Figura 1), foi constatado por Pires (2017), com uma expansão de 66\% de áreas urbanas entre os anos 2000 e 2014, a partir da comparação de dados satelitários. Além disso, Freitas (2015) identificou indícios de ilhas de calor em Palmas (TO), a partir de transectos móveis em algumas avenidas da cidade.

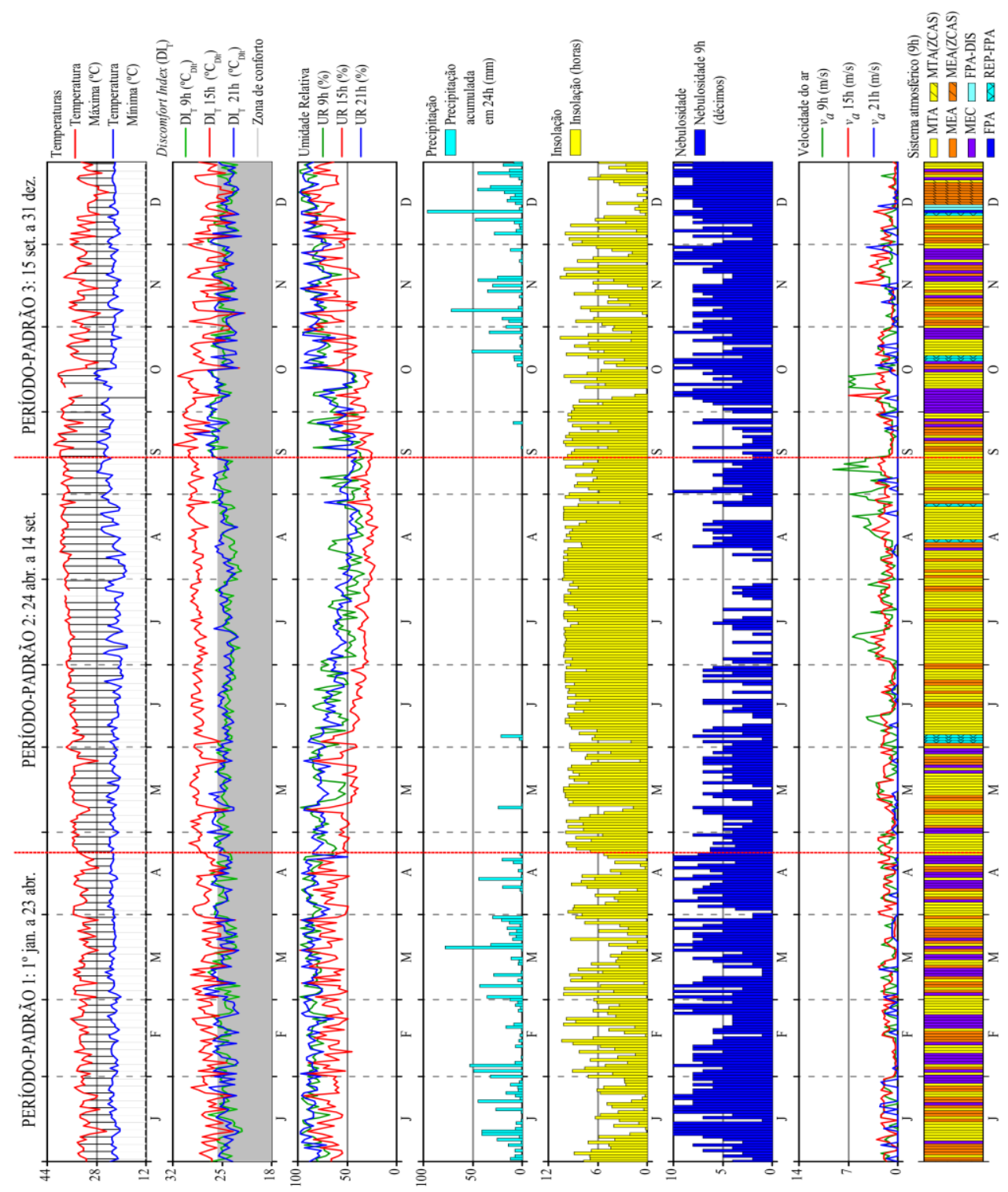

Figura 10. Gráfico de Análise rítmica da cidade de Palmas (TO), do ano de 2013. Fonte: Elaborado pela autora (2018), a partir de dados de INMET (2016). 
As temperaturas máximas variaram de 24,1 a $41,9^{\circ} \mathrm{C}$ e as mínimas de 18,1 a $28,9^{\circ} \mathrm{C}$, bem superiores ao ano de 1997, principalmente as mínimas. Mesmo com temperaturas máximas mais altas, as amplitudes foram menores que em 1997, devido às altas temperaturas mínimas de 2013. A umidade relativa obteve de 19 a $99 \%$ e os ventos não ultrapassaram 9,2m/s. Na Figura 11, a rosa dos ventos mostra a frequência anual da velocidade dos ventos por direção, em que novamente predominou a direção leste, no entanto, com percentual inferior a 1997. Não houve uma segunda predominância marcante neste ano, pois o vento teve frequências próximas em diversas outras direções. Além disso, as calmarias foram bem maiores em 2013 , chegando a $31,1 \%$, e as velocidades do vento, bem menores (com média de $1,58 \mathrm{~m} / \mathrm{s}$ ), não alcançando o intervalo de vento fresco (escala de Beaufort) e em raros momentos alcançando o intervalo de brisa forte (apenas duas vezes neste ano, como pode ser visto na Figura 10).

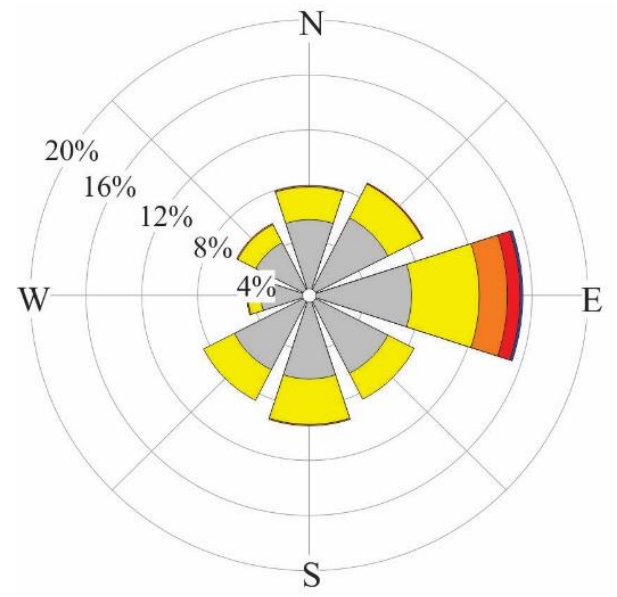

\section{3}

LEGENDA

(Escala de Beaufort)

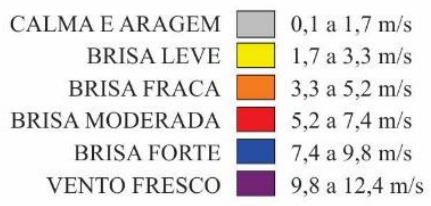

Calmarias: $31,1 \%$

Figura 11. Frequência anual da direção e velocidade dos ventos, no ano de 2013. Fonte: Elaborado pela autora (2018), a partir de dados de INMET (2016).

A direção predominante leste confirma a maior atuação da MTA sobre Palmas, mas as direções secundárias mostram um padrão um pouco diferente na distribuição das massas de ar neste ano, como visto na Figura 12. A MTA e a MEC apresentaram maior participação que em 1997, reduzindo muito a participação da MEA. Ainda, não houve nenhuma participação de massas polares em 2013, apenas de sistemas frontais que também atuaram em 1997 (FPA e REP-FPA) e da Frente Polar Atlântica em Dissipação (FPA-DIS). Na atuação dos sistemas atmosféricos nos intervalos de conforto do índice, percebeu-se uma maior participação da MTA nos intervalos de conforto, mais da metade das 
ocorrências, seguido da MEA. Nos intervalos de desconforto, ocorreu um aumento significativo da MEC em relação ao ano de 1997. Outra diferença foi a proximidade da Zona de Convergência do Atlântico Sul (ZCAS). No gráfico de análise rítmica deste ano (Figura 10), é possível identificar os dias de atuação contínua deste sistema no último mês do ano. Segundo Rodrigues (2012), a ZCAS é um sistema de umidade alta, com nebulosidade bem marcada orientada a noroeste-sudeste, desde o sul da Amazônia, passando pelas regiões Centro-Oeste e Sudeste do Brasil, até o sudoeste do Atlântico Sul, e é um dos principais sistemas atmosféricos de precipitação extrema nessas regiões ${ }^{5}$.
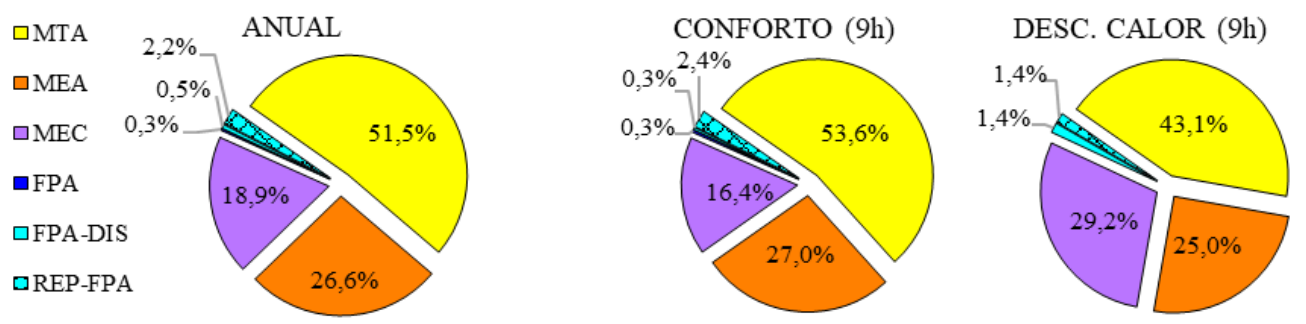

Figura 12. Frequência anual da direção e velocidade dos ventos, no ano de 2013. Fonte: Elaborado pela autora (2018), a partir de dados de INMET (2016).

O ano de 2013 foi um ano de menor precipitação que 1997, com 1848,0mm, mas bem próximo da média descrita na normal climatológica provisória 1981-2010, que foi de 1831,6mm (DINIZ; RAMOS; REBELLO, 2018). Diferente daquele ano, 2013 não esteve sob a ocorrência de El Niño ou de La Niña, (CPTEC/INPE, 2017). Apesar disso, houve maior desconforto para calor neste ano, segundo o índice DIT, possivelmente pela relativa redução da precipitação e maior urbanização que o ano de 1997.

No gráfico de análise rítmica dos dados climáticos da cidade de Palmas (TO), do ano de 2013 (Figura 10), também foi possível identificar três períodos de características similares, mas com limites diferentes do ano de 1997: o primeiro período, de 1ํ de janeiro a 23 de abril (113 dias); o segundo, de 24 de abril a 14 de setembro (144 dias); e o terceiro, de 15 de setembro a 31 de dezembro (108 dias).

\footnotetext{
${ }^{5}$ As cartas sinóticas do INPE indicaram presença também da Zona de Convergência de Umidade (ZCOU). Este sistema possui as mesmas características da ZCAS, mas com menor duração, em geral, apenas três dias, mas como há dificuldades de distingui-lo em relação à ZCAS (SACRAMENTO NETO; ESCOBAR; SILVA, 2010), manteve-se apenas a identificação desta última.
} 
Os limites de temperatura, umidade relativa, precipitação, velocidade do vento e do índice DIT, nos três períodos-padrão do ano de 2013 (Tabela 2) foram bem diferentes do ano de 1997. 0 índice apresentou o mesmo padrão do ano anteriormente analisado, com os menores valores no períodopadrão 2 e os maiores valores no período-padrão 3, assim como a temperatura mínima, no entanto, em ambos apresentou valores superiores àquele ano. Nos períodos-padrão 2 e 3, as temperaturas máximas apresentaram margens inferiores menores que em 1997, mas nos três períodos a margem superior foi bem maior, ultrapassando os $40,0^{\circ} \mathrm{C}$ no terceiro período do ano e chegando bem próximo desse valor no período-padrão 2. Diferente de 1997, as amplitudes de temperatura foram as menores do ano no período-padrão 3, enquanto as maiores novamente concentraram-se no período-padrão 2. Talvez, isso tenha ocorrido devido à maior precipitação no período-padrão 3, que no mesmo período em 1997, o que também elevou um pouco a umidade relativa. A precipitação no período-padrão 2, mesmo que pequena, também contribuiu com a diferença da umidade relativa neste período, aumentando-a levemente. Já as velocidades máximas do ar foram muito menores nos três períodos-padrão deste ano.

\begin{tabular}{|c|c|c|c|c|c|c|c|}
\hline $\begin{array}{c}\text { Período- } \\
\text { Padrão }\end{array}$ & $\begin{array}{c}\mathrm{DI}_{\mathrm{T}} \\
\text { Mín. - Máx. } \\
\left({ }^{o} \mathrm{C}_{\mathrm{DIt}}\right)\end{array}$ & $\begin{array}{c}\text { Temp. } \\
\text { Máxima } \\
\quad\left({ }^{o} \mathrm{C}\right)\end{array}$ & $\begin{array}{c}\text { Temp. } \\
\text { Mínima } \\
\left({ }^{o} \mathrm{C}\right)\end{array}$ & $\begin{array}{l}\text { Amp. temp. } \\
\text { Mín. - Máx. } \\
\quad\left({ }^{o} \mathrm{C}\right)\end{array}$ & $\begin{array}{c}\text { UR } \\
\text { Mín. - Máx. } \\
(\%)\end{array}$ & $\begin{array}{l}\text { Prec. } \\
\text { Acum. } \\
(\mathrm{mm})\end{array}$ & $\begin{array}{c}\text { Vel. } \\
\text { vento } \\
\text { Máxima } \\
(\mathrm{m} / \mathrm{s})\end{array}$ \\
\hline $1(1 / 1-23 / 4)$ & $22,2-29,4$ & $\begin{array}{c}24,8- \\
36,4\end{array}$ & $\begin{array}{l}20,2- \\
25,2\end{array}$ & $4,0-13,6$ & $45-98$ & 961,0 & 3,0 \\
\hline $\begin{array}{c}2(24 / 4- \\
14 / 9)\end{array}$ & $22,3-30,0$ & $\begin{array}{l}27,5- \\
39,9\end{array}$ & $\begin{array}{c}18,1- \\
27,9\end{array}$ & $4,2-19,9$ & $19-97$ & 49,4 & 9,2 \\
\hline $\begin{array}{c}3(15 / 9- \\
31 / 12)\end{array}$ & $21,8-32,0$ & $\begin{array}{c}24,1- \\
41,9\end{array}$ & $\begin{array}{l}19,5- \\
28,9\end{array}$ & $2,4-17,0$ & 24-99 & 837,6 & 7,0 \\
\hline
\end{tabular}

Tabela 2. Frequência anual da direção e velocidade dos ventos, no ano de 2013. Fonte: Elaborado pela autora (2018), a partir de dados de INMET (2016).

O índice $\mathrm{DI}_{\mathrm{T}}$ apresentou maiores percentuais totais de desconforto que em 1997 nos períodos-padrão 1 e 2 (Figura 13), principalmente no período-padrão 1, com diferença de mais de 10,0\% que o mesmo período no ano de 1997. Neste período, as frequências horárias tiveram um aumento significativo à noite, mais de 20,0\% que em 1997. A menor precipitação, mais de 30,0\% a menos deste mesmo período em 1997, pode ter contribuído com este aumento do desconforto, reduzindo as tardes chuvosas, assim como a maior urbanização. Já no período-padrão 2, novamente a frequência total de conforto foi a maior de todo o ano de 2013, e a menor à tarde, com quase 100,0\% de desconforto. 
Diferente do ano de 1997, os horários matutino e noturno chegaram a apresentar algum percentual de desconforto, sendo maior à noite, que pode ter ocorrido pelo efeito do aumento das áreas urbanas.

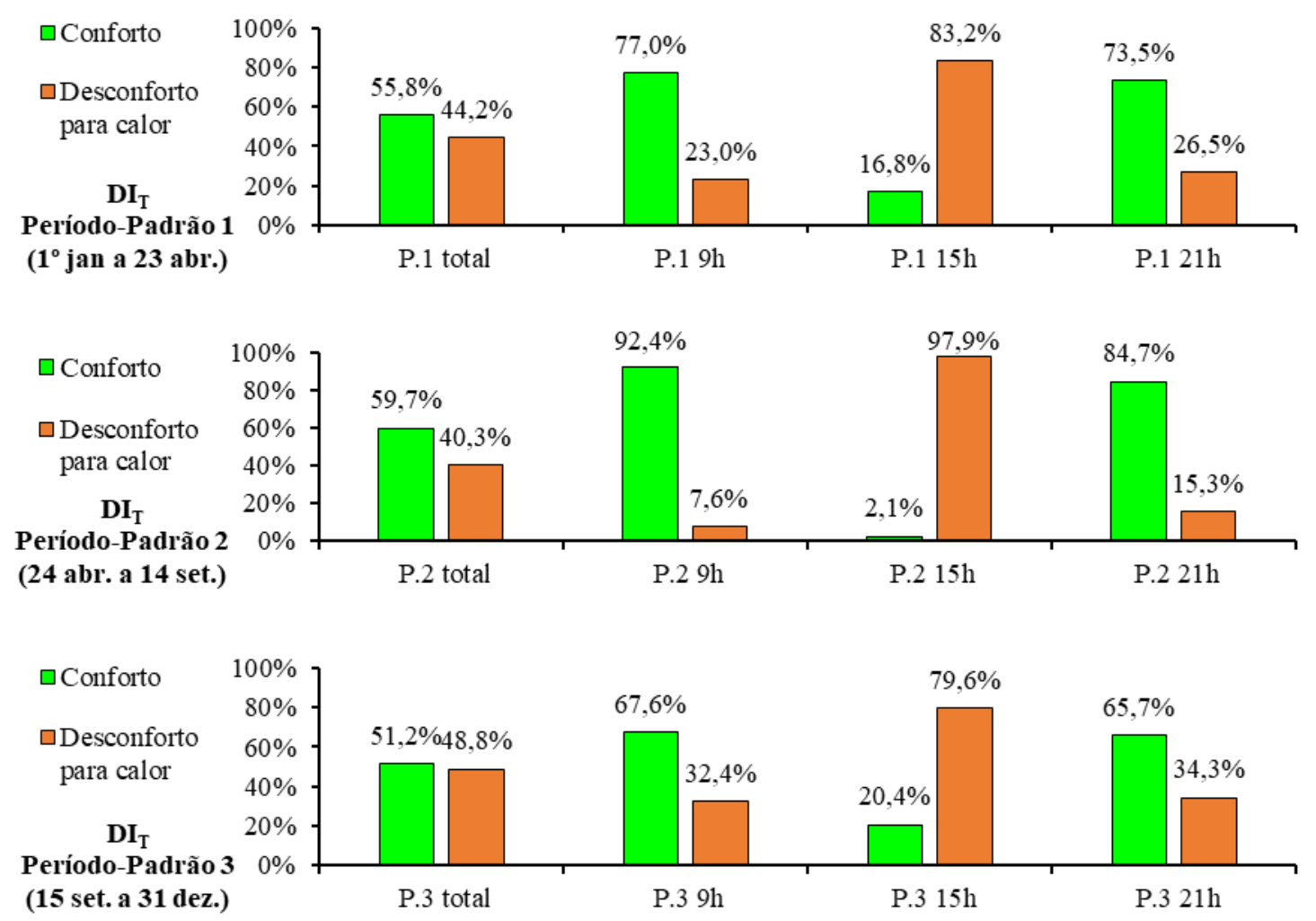

Figura 13. Frequências total e horárias do $\mathrm{DI}_{\mathrm{T}}$ nos intervalos de conforto e desconforto para o calor, nos três períodospadrão do ano de 2013. Fonte: Elaborado pela autora (2018), a partir de dados de INMET (2016).

No período-padrão 3, o comportamento foi diferente de 1997. O desconforto para o calor de uma forma geral foi levemente menor que em 1997. Na distribuição horária, foi menor pela manhã e um pouco menor à tarde que em 1997, enquanto à noite foi bem maior, mais que o dobro. Apesar das diferenças entre os anos de 1997 e 2013, este último período também se caracterizou por ter a maior frequência de desconforto pela manhã e à noite dentre os três períodos-padrão analisados, e ainda por ter alta frequência de desconforto para calor à tarde. Novamente, a maior retenção de calor pelos materiais de áreas mais urbanizadas pode ter aumentado o desconforto à noite, assim como nos outros períodospadrão analisados.

No gráfico de análise rítmica (Figura 10) foi possível perceber que, semelhante ao ano de 1997, entre o primeiro e o segundo período-padrão, o índice DIT reduziu as variações entre um dia e outro em cada 
horário analisado. Maiores oscilações do índice ocorreram nos meses de janeiro a março, tornando-se mais estável no mês de abril, quando iniciou o segundo período de forma antecipada em relação ao ano de 1997, com valores mais elevados, quando cessaram as sequências de dias chuvosos. No períodopadrão 2, a característica mais destacada foi o maior distanciamento do DIT no horário da tarde em relação ao demais horários, além de também atingir o intervalo de desconforto pela manhã e à noite em diversos momentos, diferente de 1997. Entre o segundo e o terceiro período-padrão, novamente retornam as variações ao longo dos dias, o que ocorreu de forma um pouco mais tardia que no ano de 1997, assim como ocorreu com a retomada da precipitação. O último período-padrão do ano, novamente, abrigou os maiores valores do DIT do ano, mas dessa vez alcançando o limite para uma intervenção médica, segundo Thom (1959), 32,0DIt. A partir da segunda quinzena de outubro, o índice por vezes reduziu até o intervalo de conforto, um pouco mais reduzido no mês de dezembro, com a sequência de dias chuvosos. Apesar de apresentar os valores mais altos do ano em setembro e outubro, este período apresenta valores mais baixos em dezembro, mês que contribuiu para que este período-padrão apresentasse menor percentual de desconforto em relação ao ano de 1997 . Mesmo assim, a redução do índice neste mês não foi suficiente para uma grande diferença percentual, ocorrendo uma redução de apenas $0,4 \%$ de desconforto.

Quanto aos elementos climáticos, percebeu-se comportamento semelhante ao índice, pois as oscilações deste foram acompanhadas das oscilações nas umidades relativas, nas temperaturas máximas, e na amplitude resultante. No período-padrão 1, os maiores valores de temperatura foram mais frequentes no mês de fevereiro e início de março, quando também houve menor precipitação, maior insolação e menor nebulosidade. Apesar deste período inicial, no geral, ser mais úmido que o mesmo período em 1997, apresentou-se menos úmido à noite e mais úmido pela manhã, sendo novamente possível que seja efeito da urbanização, pelo menor arrefecimento à noite.

No período-padrão 2, excetuando-se algumas quedas pontuais no mês de maio e início de junho, a temperatura máxima superou em mais de $4,0^{\circ} \mathrm{C}$ a máxima em 1997 , neste mesmo período. Os momentos de quedas pontuais ocorreram com menor insolação, maior nebulosidade, próximo aos raros dias de precipitação deste período central. As maiores amplitudes de temperatura deste ano 
concentraram-se no mês de agosto, mas com valores mais baixos que em 1997, influenciados também pela elevação das mínimas. No início do período-padrão 3, as temperaturas foram as mais elevadas do ano, chegando a $41,9^{\circ} \mathrm{C}$ em setembro. No final, ocorreram temperaturas máximas mais baixas, mas mínimas não tão reduzidas, gerando menores amplitudes, muito semelhante ao período-padrão 1. Nos dias de redução do índice no mês de dezembro, ocorreu precipitação em dias consecutivos, menor duração da insolação e maior nebulosidade.

No primeiro período-padrão do ano, a velocidade do vento em raros momentos ultrapassou os $2,5 \mathrm{~m} / \mathrm{s}$ (aragem na escala de Beaufort), enquanto nos demais períodos, as velocidades atingiram $9,2 \mathrm{~m} / \mathrm{s}$, porém, de forma pontual. Nos gráficos da Figura 14, com a direção e a velocidade dos ventos nos três períodos-padrão, também é possível verificar que as maiores velocidades do vento ocorreram no período-padrão 2, na direção leste e adjacentes. Os períodos-padrão 1 e 3 apresentaram menores velocidades (principalmente o primeiro período), com pequena predominância nas direções sul e norte, respectivamente. Diferente do ano de 1997, os períodos-padrão 1 e 3 apresentaram uma distribuição mais homogênea, com frequências próximas em diversas direções, demonstrando a atuação de vários sistemas atmosféricos nestes períodos. Outra característica foi a maior frequência de calmarias noturnas que em 1997, o que também contribui para a dificuldade de dispersão do calor acumulado ao longo do dia na cidade, favorecendo a manifestação das ilhas de calor, segundo Gartland (2010).
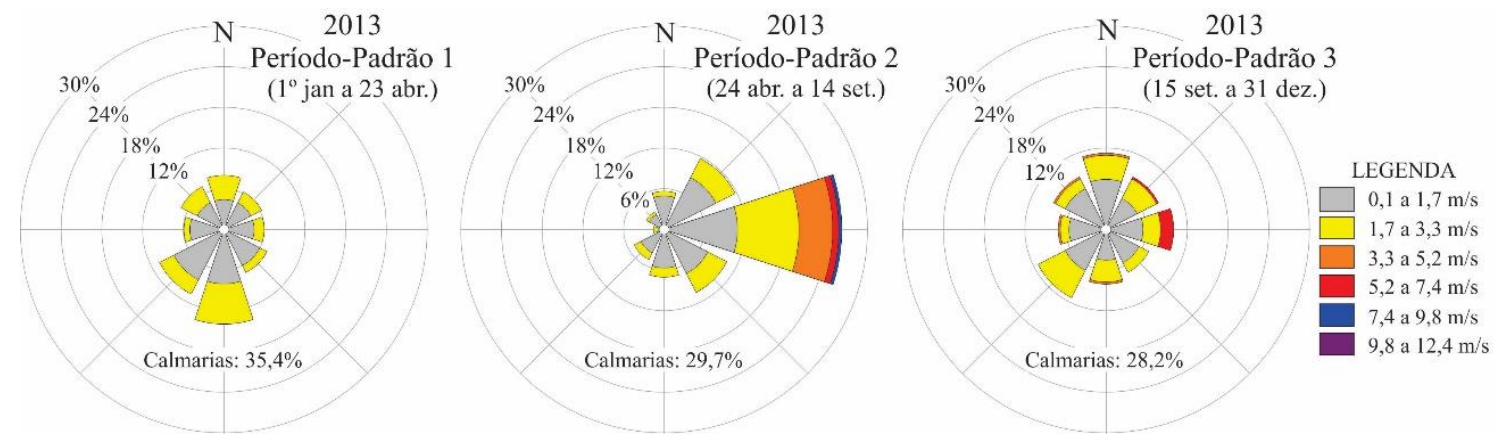

Figura 14. Frequência da direção e velocidade dos ventos nos três períodos-padrão do ano de 2013. Fonte: Elaborado pela autora (2018), a partir de dados de INMET (2016).

A direção predominante no segundo período indica maior frequência da MTA, que possui direção preferencialmente leste, diferente do primeiro e terceiro períodos, com a maior diversidade de direções. 
Semelhante ao ano de 1997, na Figura 15, é possível identificar a predominância da MTA nos três períodos-padrão, mas com frequência bem superior no período-padrão 2, ainda maior que em 1997, e a menor participação da MEA e da MEC. Nos períodos-padrão 1 e 3, os três sistemas principais (MTA, MEA e MEC) apresentaram frequências muito próximas, com leve predominância da MTA. Em comparação aos mesmos períodos em 1997, o período-padrão 1 apresentou percentual um pouco maior da MEC, reduzindo a participação tanto da MEA como da MTA, enquanto o período-padrão 3 mais que duplicou a participação da MEC, reduzindo bem mais a participação da MEA e MTA. No terceiro período também ocorreu a maior participação das frentes $(5,6 \%)$, que também atuaram, de forma mais discreta, no segundo período $(3,5 \%)$.
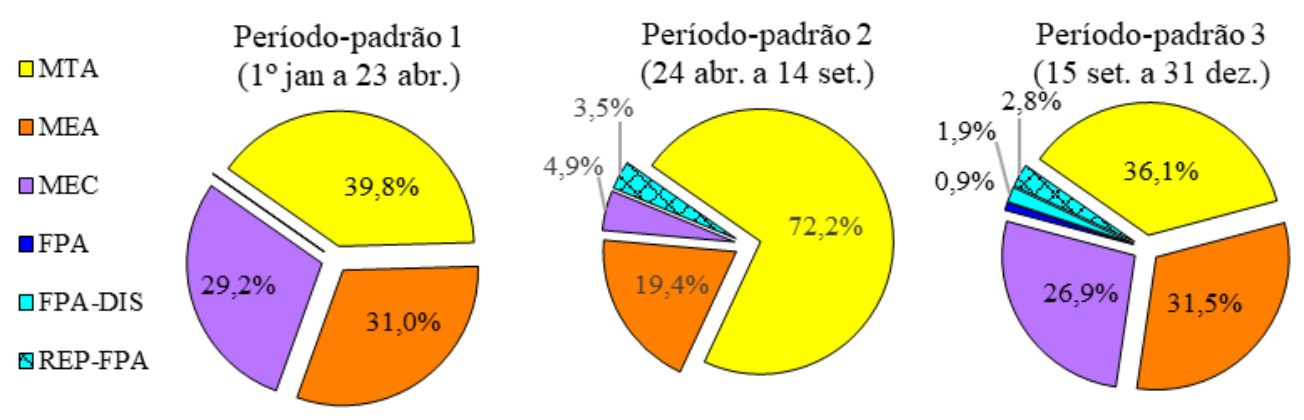

Figura 15. Frequência dos sistemas atmosféricos atuantes nos períodos-padrão do ano de 2013. Fonte: Elaborado pela autora (2018), a partir de dados de INMET (2016).

No período-padrão 1, os sistemas atmosféricos atuaram de forma menos sequencial que em 1997 (ver Figura 10). Já no segundo período, verificou-se mais sequências da MTA, em junho, julho e agosto, enquanto em 1997, as sequências foram concentradas apenas no mês de julho. No terceiro períodopadrão do ano, os dias de redução do índice no mês de dezembro ocorreram sob atuação da MEA em sequência, mas com proximidade de atuação da ZCAS. Os sistemas polares e frontais apareceram na segunda fase do período, mas, novamente, não interferiram no índice de conforto.

Resumindo, o período-padrão 1 apresentou características semelhantes ao mesmo período em 1997, no entanto, com temperaturas máximas e índices mais elevados que naquele ano, maior nebulosidade e menor insolação. Este período apresentou ainda, menor precipitação que em 1997, com noites mais quentes e desconfortáveis, e oscilação caracterizada por mudanças pontuais dos elementos climáticos. 
Teve menor duração que o mesmo período em 1997, com finalização antecipada de meados de maio para final de abril, mas ainda coincidindo com boa parte do verão e início do outono.

O período-padrão 2, de forma semelhante ao ano de 1997, teve menor variação dos elementos que 0 período anterior, sendo caracterizado por temperaturas e amplitudes térmicas crescentes, menores umidades, precipitação muito reduzida, maior insolação, menor nebulosidade. No entanto, os valores do índice e das temperaturas foram muito superiores ao ano de 1997, com menores velocidades do vento (mesmo que maiores que os outros períodos do ano) e consequentemente maior frequência de calmarias que naquele ano. Coincidiu com maior parte do outono e praticamente todo o inverno.

Já o período-padrão 3, que ocorreu durante a primavera (com alguns dias do inverno no início do período e alguns dias do verão no final), apresentou um ritmo oscilante entre tipos de tempo estáveis e instáveis, com os valores mais críticos do ano no início do período. Houve redução dos valores máximos do índice, das temperaturas e das amplitudes de temperatura, ao final do período, no mês de dezembro. Assim como no ano de 1997, o índice apresentou maior desconforto à tarde no início do período, influenciado pela altura solar somada à ausência da precipitação e nebulosidade, mas diferente daquele ano, as noites foram tão ou mais desconfortáveis que as manhãs. No mês de dezembro, o índice reduziu com o aumento da pluviosidade e nebulosidade, e aumento da umidade relativa. Uma característica desse período foi a atuação da ZCAS, no âmbito da MEA e da MTA, que influenciou diretamente na redução do $\mathrm{DI}_{\mathrm{T}}$

\section{CONCLUSÕES}

O ritmo climático no ano de 1997, na cidade de Palmas (TO), apresentou semelhanças com o descrito por estudos climáticos do Estado do Tocantins, como Pinto (2013; 2017), Silva (2013), Souza, Gomes e Rocha (2014) e Souza (2016), quanto à atuação dos sistemas atmosféricos, apresentando predominância da MTA durante todo o ano, mas com características diferentes nos três períodospadrão, principalmente no período-padrão 2 (inverno). Já a MEA foi mais frequente nos períodospadrão 1 e 3 (primavera-verão), ambos chuvosos, e menos frequente no inverno, enquanto a MEC ocorreu com maior frequência no período-padrão 1, em fevereiro (verão) e raramente no inverno. Os 
sistemas polares e frontais apareceram muito sutilmente, demonstrando a fragilidade na sua atuação na cidade, como descrito por Souza (2016), ocorrendo no período-padrão 3 (primavera), de outubro a dezembro, mas também ocorreram em julho (período-padrão 2).

Da mesma forma que Souza, Gomes e Rocha (2014), também foram verificadas diferenças mais acentuadas entre a estação chuvosa (primavera-verão) e a estação seca (outono-inverno), no caso, entre o período-padrão 2 (período seco), e os períodos-padrão 1 e 3 (períodos chuvosos). Ou seja, as diferenças foram mais marcantes no período central, pela ausência de precipitação, maior insolação, maior ventilação, menor nebulosidade e amplitude térmica, enquanto os períodos-padrão 1 e 3 sempre apresentavam alguma semelhança. Também foi possível identificar os extremos, a partir de episódios de calor excessivo, no período-padrão 3, principalmente em setembro e outubro, e de pluviosidade acentuada no período-padrão 1, por vezes intensa e pontual, e por vezes menos intensa, mas de forma contínua.

Já o ano de 2013, apesar das semelhanças em traços gerais, apresentou algumas diferenças pontuais com o padrão descrito nestes estudos climáticos citados. Quanto à atuação dos sistemas atmosféricos, o ano de 2013 apresentou predominância da MTA na cidade de Palmas (TO) durante todo o ano, com características diferentes no segundo período-padrão em relação aos demais, como é típico no Estado. A MEA teve menor atuação em todos os três períodos-padrão, reduzindo muito no período-padrão $2 \mathrm{e}$ 3, devido à maior atuação da MTA no segundo e da MEC no terceiro. A MEC também atuou o ano todo, um pouco mais frequente no período-padrão 1 (verão), bem mais frequente que 1997 no períodopadrão 3 (primavera), e sendo mais rara ainda no período-padrão 2 (inverno). A maior atuação da MEC pode ter sido favorecida, em outubro e novembro de 2013, por um maior afastamento do vórtice da MTA para o leste do Atlântico, que por sua vez foi resultante também dos avanços da MPA. Neste ano, como a MPA esteve mais forte, segundo análises sinóticas do INPE (CPTEC/INPE, 2016), acabou por impulsionar a MTA para leste do oceano, deixando condições propícias à atuação da MEC no Tocantins. No entanto, não ocorreram sistemas polares na cidade, talvez também pelo posicionamento bem marcante da ZCAS, que influenciou na redução da insolação e das temperaturas máximas, aumentou a nebulosidade, mantendo níveis constantes de precipitação e repercutindo em maior conforto no índice DIT. Já os sistemas frontais foram um pouco mais frequentes que em 1997, 
ocorrendo tanto no período-padrão 3 (apenas na primavera), como no período-padrão 2 (no final do outono e no inverno), mesmo que com frequência ainda muito pequena.

Além disso, o ritmo de atuação dos sistemas atmosféricos foi determinado pela maior alternância das massas de ar no ano de 2013 (o que se refletiu no índice de conforto), tanto no início, como no final do ano. No ano de 1997, nestes períodos, houve maior sequência de atuação de um mesmo sistema atmosférico, geralmente da MEA e MTA. No ano de 2013, ocorreram apenas duas sequências significativas de atuação de um mesmo sistema, uma com a MEC e outra com a MEA, ambas no período-padrão 3. No período-padrão 2, ocorreu o contrário, o ano de 2013 apresentou menos alternâncias de tipos de tempo, com mais sequências da MTA que em 1997.

Em termos de ritmo, verificaram-se ainda outras diferenças entre os anos analisados. No ano de 1997, choveu mais no início do ano, com melhor distribuição e chuvas mais intensas de janeiro a março. No final do ano, choveu bem menos que no início, mas os episódios ocorreram de forma contínua, começando em setembro, com totais diários menos expressivos, mas que abrangeram um maior número de dias. Em 2013, choveu menos no início do ano do que em 1997, com a chuva já se tornando escassa no mês de abril. No final do ano, apesar de ter volume superior a 1997, os episódios foram mais concentrados em alguns dias, e só iniciaram de forma mais sequencial na segunda quinzena de outubro. Na ventilação, em 2013 houve forte predominância das calmarias noturnas durante todo o ano, muito superior que o ano de 1997, quando estavam concentradas na estação seca.

0 índice de conforto $\mathrm{DI}_{\mathrm{T}}$ apresentou algumas diferenças no ritmo em 1997 e em 2013. Apesar do índice apresentar maior variação e menor amplitude no início e no final dos dois anos, com maior estabilidade e amplitude na estação seca no ano de 1997, ano confortável, o índice apresentou menor variação de um dia para o outro que em 2013, ano desconfortável. Além disso, o período de estabilidade atmosférica foi bem maior no ano de 2013 , começando ainda em abril e terminando mais tardiamente em setembro, com valores bem superiores ao ano de 1997, com episódios de calor excessivo, ainda maiores em setembro e outubro de 2013. Entende-se que, como destacado por Monteiro (1971), baseado no conceito sorreano, não só os totais, mas a forma como os tipos de tempo se sucedem, ou seja, o ritmo climático, é imprescindível para a compreensão do clima e, 
consequentemente, para o entendimento dos efeitos decorrentes deste sobre o conforto e o desconforto térmico das pessoas.

\section{REFERÊNCIAS}

AYOADE, Johnson Olaniyi. Introdução à climatologia para os trópicos. 4. ed. Rio de Janeiro: Bertrand Brasil, 1996. 332 p.

CENTRO DE PREVISÃO DE TEMPO E ESTUdos ClimÁticos. Instituto Nacional de Pesquisas Espaciais (CPTEC/INPE). El niño e la niña. Disponível em: http://enos.cptec.inpe.br/. Acesso em: 25 mar. 2017.

Tempo. Análise Sinótica. Disponível em: <http://tempo.cptec.inpe.br/>. Acesso em: 12 ago. 2016.

DE FREITAS, Christopher R.; GRIGORIEVA, Elena A. A comparison and appraisal of a comprehensive range of human thermal climate indices. International Journal of Biometeorology, v. 61, n. 3, p. 487-512, mar. 2017.

DINIZ, Francisco de Assis; RAMOS, Andrea Malheiros; REBELLO, Expedito Ronald Gomes. Brazilian climate normals for 1981-2010. Pesquisa Agroecuária Brasileira. Brasília, v. 53, n.2, p. 131-143, fev. 2018.

FREITAS, Thyago Phellip França. 0 campo térmico de Palmas/To em episódios de primavera-verão e de outonoinverno: contribuições ao planejamento urbano. 2015. 160 p. Dissertação (Mestrado em Ciências do Ambiente) Universidade Federal do Tocantins, Palmas, 2015.

FROTA, Anésia Barros; SCHIFFER, Sueli Ramos. Manual de conforto térmico. 5. ed. São Paulo: Studio Nobel, 2001.

GARTLAND, Lisa. Ilhas de calor: como mitigar zonas de calor em áreas urbanas. Tradução de Silvia Helena Gonçalves. São Paulo: Oficina de Textos, 2010. 231 p.

GILES, Brian D.; BALAFOUTIS, Christos; MAHERAS, Panyotis. Too hot for comfort: The heatwaves in Greece in 1987 and 1988. International Journal of Biometeorology, v. 34, n. 2, p. 98-104, jun. 1990.

HANN, Julius. Handbuch der Klimatologie. 3. ed. v. 1, Allgemeine Klimalehre. Stuttgart: Verlag Von J. Engelhorn, 1908.

HUMPHREYS, Michael A. Field studies of thermal comfort compared and applied. In: SYMPOSIUM ON PHYSIOLOGICAL REQUIREMENTS OF THE MICROCLIMATE, set. 1975, Praga. Proceedings... Praga: Building Research Establishment, 1975.

Instituto NACIONAL DE MEteorologia (INMET). Banco de Dados Meteorológicos para Ensino e Pesquisa (BDMEP), 2015. Disponível em: http://www.inmet.gov.br/portal/index.php?r=bdmep/bdmep. Acesso em: 20 mar. 2015.

IQBAL, Muhammad. An introduction to solar radiation. Nova Iorque: Academic Press, 1983.

LANDSBERG, Helmut Erich. The assessment of human bioclimate: a limited review of physical parameters. World Meteorological Organization, Technical Note n. 123. Genebra, Suíca: WMO, 1972.

MONTEIRO, Carlos Augusto de Figueiredo. Análise rítmica em climatologia: problemas da atualidade climática em São Paulo e achegas para um programa de trabalho. São Paulo: Universidade de São Paulo/Instituto de Geografia, 1971. Série Climatologia, 1 . 
PINTO, Paulo Henrique Pereira. As chuvas no Estado do Tocantins: distribuição geográfica e gênese das variações rítmicas. 2013. 183 p. Dissertação (Mestrado em Geografia) - Instituto de Geociências e Ciências Exatas, Universidade Estadual Paulista, Rio Claro, SP, 2013.

A Vulnerabilidade Socioambiental na Bacia Hidrográfica do Rio Palma, Estado do Tocantins, Brasil. 2017.147 p. Tese (Doutorado em Geografia) - Instituto de Geociências e Ciências Exatas, Universidade Estadual Paulista, Rio Claro, SP, 2017.

PIRES, Érika Gonçalves. Avaliação de parâmetros biofísicos, derivados de dados satelitários, na área de influência do reservatório da UHE Luís Eduardo Magalhães - TO. 2017. 224 p. Tese (Doutorado em Geografia) - Instituto de Estudos Socioambientais, Universidade Federal de Goiás, Goiânia, 2017.

RODRIGUES, Herika Pereira. Zona de convergência do Atlântico Sul: um estudo observacional e numérico. 2012.67 p. Dissertação (Mestrado em Meteorologia) - Universidade Federal de Campina Grande, Campina Grande, PB, 2012.

RODRIGUES, Marcely Pereira da Silveira. A natureza da verticalização no processo de reprodução do espaço urbano em Palmas-TO. 2016. 105 p. Dissertação (Mestrado em Geografia) - Universidade Federal do Tocantins, Porto Nacional, TO, 2016 .

SACRAMENTO NETO, Olivio Bahia do; ESCOBAR, Gustavo Carlos Juan; SILVA, Philipp Edson Dias da. Método objetivo para identificar episódios de Zonas de Convergência de Umidade (ZCOU) no ambiente operacional do Centro de Previsão de Tempo e Estados Climáticos - CPTEC. In: CONGRESso BRASILEIRO DE METEOROLOGIA, 16., set. 2010, Belém. Anais... Belém: Sociedade Brasileira de Meteorologia, 2010.

SILVA, Aion Angelu Ferraz. Variações no ritmo pluvial e a produção de soja no Município de Pedro Afonso-TO. 2013. 229 p. Dissertação (Mestrado em Geografia) - Universidade Federal do Tocantins, Porto Nacional, TO, 2013.

SILVA, Liliane Flávia Guimarães da; SOUZA, Lucas Barbosa e. Caracterização da direção predominante e velocidade do vento em Palmas (TO). In: SIMPÓSIO BRASILEIRO DE CLIMATOLOGIA GEOGRÁFICA, 12., out. 2016, Goiânia. Anais... Goiânia: Associação Brasileira de Climatologia, 2016. p. 1210-1221.

Seleção de anos-padrão para análise rítmica em estudos de conforto térmico: uma proposta de "Confortogramas" a partir de índices. Revista Brasileira de Climatologia, Curitiba, Universidade Federal do Paraná, v. 13, n. 20, p. 52-70, jan./jul. 2017.

SORRE, Maximilien. Le Climat. In: Les fondements de la Géographie Humaine. Tome I: Les fondements biologiques. Essai d'une écologie de l'homme. Livre I: Lê climat et l’homme. 3. ed. Paris: Librairie Armand Colin, 1951. cap. 1, p. 1343.

Objeto e método da climatologia. Tradução José Bueno Conti. Revista do Departamento de Geografia, São Paulo, Universidade de São Paulo, v. 18, p. 89-94, 2006.

SOUZA, Lucas Barbosa e. Ritmo climático e tipos de tempo no Estado do Tocantins, Brasil. In: SIMPÓSIO BRASILEIRO DE Climatologia GEOGRÁfiCA, 12., out. 2016, Goiânia. Anais... Goiânia: Associação Brasileira de Climatologia, 2016. p. $2266-2277$.

SOUZA, Lucas Barbosa e; GOMES, Luam Patrique Oliveira; ROCHA, Enedina Maria Campos. Participação dos sistemas atmosféricos no Estado do Tocantins: o exemplo do ano habitual de 2001. In: SIMPÓSIO BRASILEIRO DE Climatologia GeográfiCA, 11., out. 2014, Curitiba. Anais... Curitiba: Associação Brasileira de Climatologia, 2014. p. $1533-1544$.

THOM, Earl Crabill. The Discomfort Index. Weatherwise, v. 12, n. 2, p. 57-61, abr. 1959. 